\title{
S. aureus Infections in Chicago, 2006-2014: Increase in CA MSSA and Decrease in MRSA Incidence - ERRATUM
}

In the article by Acree, et al. ${ }^{1}$, an error introduced during the production process resulted in the initial header for Table 3 incorrectly reading "MSSA Blood Isolates $(\mathrm{n}=578)$." The correct header should read "MRSA SSTI Isolates $(\mathrm{n}=3,940)$." The entire corrected table appears below. The publisher apologizes to the authors and readers for this error.

\section{REFEREN C E}

1. Acree ME, Morgan E, David MZ. S. aureus Infections in Chicago, 2006-2014: Increase in CA MSSA and Decrease in MRSA Incidence. Infection Control Hosp Epidemiol 2017; 38:1226-1234.

тав Isolates, by Year, University of Chicago Medicine, 2006-2014

\begin{tabular}{|c|c|c|c|c|c|c|}
\hline \multicolumn{7}{|c|}{ MRSA SSTI Isolates $(\mathrm{n}=3,940)$} \\
\hline & Gentamicin $^{\mathrm{a}}$ & Erythromycin & Rifampin & Tetracycline $^{\mathrm{b}}$ & Ciprofloxacin ${ }^{\mathrm{b}}$ & Clindamycin $^{\mathrm{b}}$ \\
\hline Year & $\begin{array}{c}\text { No. } \\
\text { (\% susceptible) }\end{array}$ & $\begin{array}{c}\text { No. } \\
\text { (\% susceptible) }\end{array}$ & $\begin{array}{c}\text { No. } \\
\text { (\% susceptible) }\end{array}$ & $\begin{array}{c}\text { No. } \\
\text { (\% susceptible) }\end{array}$ & $\begin{array}{c}\text { No. } \\
\text { (\% susceptible) }\end{array}$ & $\begin{array}{c}\text { No. } \\
\text { (\% susceptible) }\end{array}$ \\
\hline 2006 & $576(100.0)$ & $45(7.8)$ & $571(99.1)$ & $575(99.8)$ & $483(83.9)$ & $502(87.2)$ \\
\hline 2007 & $543(100.0)$ & $41(7.6)$ & $543(100.0)$ & $542(99.8)$ & $448(82.5)$ & $451(83.1)$ \\
\hline 2008 & $556(100.0)$ & $49(8.8)$ & $554(99.6)$ & $556(100.0)$ & $459(82.6)$ & $467(84.0)$ \\
\hline 2009 & $476(100.0)$ & $37(7.8)$ & $473(99.4)$ & $475(99.8)$ & $360(75.6)$ & $386(81.1)$ \\
\hline 2010 & $481(100.0)$ & $45(9.4)$ & $475(98.8)$ & $481(100.0)$ & $369(76.7)$ & $392(81.5)$ \\
\hline 2011 & $423(100.0)$ & $41(9.7)$ & $422(99.5)$ & $414(97.6)$ & $352(83.2)$ & $332(78.3)$ \\
\hline 2012 & $384(100.0)$ & $38(9.9)$ & $383(99.7)$ & $357(93.0)$ & $281(73.2)$ & $297(77.3)$ \\
\hline 2013 & $400(100.0)$ & $40(10.0)$ & $398(99.5)$ & $386(96.5)$ & $286(71.5)$ & $317(79.3)$ \\
\hline 2014, Q1 & $100(100.0)$ & $11(11.0)$ & $98(98.0)$ & $92(92.0)$ & $68(68.0)$ & $70(70.0)$ \\
\hline \multicolumn{7}{|c|}{ MSSA SSTI Isolates $(\mathrm{n}=3,006)$} \\
\hline & Gentamicin $^{\mathrm{a}}$ & Erythromycin & Rifampin & Tetracycline $\mathrm{e}^{\mathrm{b}}$ & Ciprofloxacin & Clindamycin $^{\mathrm{b}}$ \\
\hline Year & $\begin{array}{c}\text { No. } \\
\text { (\% susceptible) }\end{array}$ & $\begin{array}{c}\text { No. } \\
\text { (\% susceptible) }\end{array}$ & $\begin{array}{c}\text { No. } \\
\text { (\% susceptible) }\end{array}$ & $\begin{array}{c}\text { No. } \\
\text { (\% susceptible) }\end{array}$ & $\begin{array}{c}\text { No. } \\
\text { (\% susceptible) }\end{array}$ & $\begin{array}{c}\text { No. } \\
\text { (\% susceptible) }\end{array}$ \\
\hline 2006 & $348(100.0)$ & $239(68.7)$ & $346(99.4)$ & $348(100.0)$ & $334(96.0)$ & $332(95.4)$ \\
\hline 2007 & $351(100.0)$ & $236(67.2)$ & $349(99.4)$ & $351(100.0)$ & $338(96.3)$ & $317(90.3)$ \\
\hline 2008 & $322(100.0)$ & $205(63.7)$ & $322(100.0)$ & $322(100.0)$ & $301(93.5)$ & $252(78.3)$ \\
\hline 2009 & $360(100.0)$ & $252(70.0)$ & $360(100.0)$ & $360(100.0)$ & $337(93.6)$ & $306(85.0)$ \\
\hline 2010 & $383(100.0)$ & $255(66.6)$ & $383(100.0)$ & $383(100.0)$ & $359(93.7)$ & $310(80.9)$ \\
\hline 2011 & $331(100.0)$ & $206(62.2)$ & $331(100.0)$ & $323(97.6)$ & $319(96.4)$ & $259(78.3)$ \\
\hline 2012 & $365(100.0)$ & $254(69.6)$ & $365(100.0)$ & $348(95.3)$ & $347(95.1)$ & $305(83.4)$ \\
\hline 2013 & $436(100.0)$ & $278(63.8)$ & $435(99.7)$ & $405(92.9)$ & $413(71.7)$ & $356(81.7)$ \\
\hline 2014, Q1 & $110(100.0)$ & $73(66.4)$ & $109(99.1)$ & $105(95.5)$ & $101(91.8)$ & $93(84.6)$ \\
\hline \multicolumn{7}{|c|}{ MRSA Blood Isolates $(\mathrm{n}=458)$} \\
\hline & Gentamicin $^{\mathrm{a}}$ & Erythromycin & Rifampin & Tetracycline $^{\mathrm{b}}$ & Ciprofloxacin & Clindamycin \\
\hline Year & $\begin{array}{c}\text { No. } \\
\text { (\% susceptible) }\end{array}$ & $\begin{array}{c}\text { No. } \\
\text { (\% susceptible) }\end{array}$ & $\begin{array}{c}\text { No. } \\
(\% \text { susceptible })\end{array}$ & $\begin{array}{c}\text { No. } \\
(\% \text { susceptible })\end{array}$ & $\begin{array}{c}\text { No. } \\
\text { (\% susceptible) }\end{array}$ & $\begin{array}{c}\text { No. } \\
\text { (\% susceptible) }\end{array}$ \\
\hline 2006 & $82(100.0)$ & $8(9.8)$ & $77(93.9)$ & $82(100.0)$ & $32(39.0)$ & $38(46.3)$ \\
\hline 2007 & $67(100.0)$ & $9(13.4)$ & $66(98.5)$ & $67(100.0)$ & $23(34.3)$ & $33(49.3)$ \\
\hline 2008 & $45(100.0)$ & $5(11.1)$ & $44(97.8)$ & $45(100.0)$ & $22(48.9)$ & $26(57.8)$ \\
\hline 2009 & $62(100.0)$ & $7(11.3)$ & $62(100.0)$ & $62(100.0)$ & $26(41.9)$ & $33(53.2)$ \\
\hline 2010 & $45(100.0)$ & $0(0.0)$ & 43 (95.6) & $45(100.0)$ & $19(41.9)$ & $17(37.8)$ \\
\hline 2011 & $41(100.0)$ & $2(4.9)$ & $39(95.1)$ & $40(97.6)$ & $27(65.9)$ & $21(51.2)$ \\
\hline 2012 & $53(100.0)$ & $6(11.3)$ & $52(98.1)$ & $44(83.0)$ & $17(32.8)$ & $28(52.8)$ \\
\hline 2013 & $44(100.0)$ & $6(13.6)$ & $43(97.7)$ & 39 (88.6) & $18(40.9)$ & $25(56.8)$ \\
\hline 2014, Q1 & $19(100.0)$ & $1(5.3)$ & $18(94.7)$ & $13(68.4)$ & $5(26.3)$ & $6(31.6)$ \\
\hline
\end{tabular}


TABLE 3. Continued

MSSA Blood Isolates $(n=578)$

\begin{tabular}{|c|c|c|c|c|c|c|}
\hline & Gentamicin $^{\mathrm{a}}$ & Erythromycin & Rifampin & Tetracycline $^{\mathrm{b}}$ & Ciprofloxacin & Clindamycin \\
\hline Year & $\begin{array}{c}\text { No. } \\
\text { (\% susceptible) }\end{array}$ & $\begin{array}{c}\text { No. } \\
\text { (\% susceptible) }\end{array}$ & $\begin{array}{c}\text { No. } \\
\text { (\% susceptible) }\end{array}$ & $\begin{array}{c}\text { No. } \\
\text { (\% susceptible) }\end{array}$ & $\begin{array}{c}\text { No. } \\
\text { (\% susceptible) }\end{array}$ & $\begin{array}{c}\text { No. } \\
\text { (\% susceptible) }\end{array}$ \\
\hline 2006 & $92(100.0)$ & $67(72.8)$ & $92(100.0)$ & 91 (98.9) & $86(92.4)$ & $85(92.4)$ \\
\hline 2007 & $79(100.0)$ & $59(74.7)$ & $79(100.0)$ & $79(100.0)$ & $74(93.7)$ & $68(86.1)$ \\
\hline 2008 & $71(100.0)$ & $51(71.8)$ & $70(98.6)$ & $71(100.0)$ & $60(84.5)$ & $57(80.3)$ \\
\hline 2009 & $55(100.0)$ & $48(87.3)$ & $55(100.0)$ & $55(100.0)$ & $52(94.6)$ & $50(90.9)$ \\
\hline 2010 & $62(100.0)$ & $44(71.0)$ & $62(100.0)$ & $62(100.0)$ & 57 (91.9) & $47(75.8)$ \\
\hline 2011 & $59(100.0)$ & $44(74.6)$ & $59(100.0)$ & $58(98.3)$ & $58(98.3)$ & $50(84.8)$ \\
\hline 2012 & $65(100.0)$ & $51(78.5)$ & $65(100.0)$ & $62(95.4)$ & $62(95.4)$ & $53(81.5)$ \\
\hline 2013 & $77(100.0)$ & $56(72.7)$ & $77(100.0)$ & $74(96.1)$ & $71(92.2)$ & $65(84.4)$ \\
\hline 2014, Q1 & $18(100.0)$ & $12(66.7)$ & $18(100.0)$ & $17(94.4)$ & $17(94.4)$ & $14(77.8)$ \\
\hline
\end{tabular}

NOTE. MSSA, methicillin-susceptible Staphylococcus aureus; MRSA, methicillin-resistant Staphylococcus aureus; Q1, first quarter of the year; SSTI, skin and soft tissue infection.

${ }^{\mathrm{a}}$ No resistant isolates were observed for gentamicin.

${ }^{\mathrm{b}}$ Significant decrease $(\mathrm{P}<0.05)$. 